Foundation (NSF). It is not a perfect system, but it has served US science well for more than 50 years and it has the sort of autonomy to which the ERC should aspire. All would agree that, like the NSF, the ERC should be a competitive organization for bottom-up basic research, funding researchers from across all disciplines and from across the continent, solely on the basis of excellence.

But 'autonomy' means different things to different people. For some, it means as complete a dissociation as is possible from the European Commission. History might seem to support this argument, even though it will be the commission that will be footing the bill, likely to be up to $€ 1.5$ billion (US $\$ 1.8$ billion) per year. The commission's customary bureaucracy has never failed to alienate researchers.

But the commission can in this case play a useful role in sheltering the new-born agency from interference by competing national interests. Opponents of management by the commission have latched on to a hitherto unused article in the rules governing commission research, which allows a separate agency to be set up to run a particular programme. At an informal meeting of research ministers of the European Union's 25 member states in Cardiff earlier this month, opinion was equally divided between the merits of this and a commission-led agency.

It may already be too late for the more independent agency to be in place at the start, if the ERC is to be launched in 2007 as planned. Its establishment and location would require approval by both the European council of ministers and the European parliament - bodies that stretched out the decision to create the somewhat analogous European food agency over three years in an acrimonious and heavily politicized struggle.

Even more dangerously, there is a strong possibility that the agency would establish a decision-making board filled with national representatives. In contrast, a commission-run agency would have only a five-strong steering committee to ensure that it executes appropriately the will of its scientific council.

European experience demonstrates time and again that when the European Union's member nations get too closely involved, their diverse individual goals distort agendas and delay decisions. One of the commission's cardinal roles is to shelter the implementation of European policies from the distorting effects of national interests.

The best way forward is therefore to set up the ERC as a commission-led agency with the option of switching to a more independent operation “Experience demonstrates time and again that when Europe's member nations become involved, their individual goals distort agendas and delay decisions."

later if it proves desirable. The commission would then have time to prove that it can run an agency capable of executing the desires of its scientific council without debilitating bureaucracy. Better to live in hope than to sacrifice the ERC to the certain buffeting between the conflicting fancies of Europe's 25 member states.

\section{Independence at the top}

\section{The US Food and Drug Administration badly needs some strong and stable leadership.}

( n 18 July, the US Senate finally confirmed Lester Crawford as commissioner of the Food and Drug Administration (FDA). Crawford has been acting commissioner since March 2004. This critically important agency has lacked a confirmed leader for more than half of President George W. Bush's tenure - and the cracks are beginning to show.

Crawford, a pharmacologist, veterinarian and member of the Institute of Medicine, has previously held senior positions at both the FDA and the Department of Agriculture. In 2002 and 2003 he was the FDA's deputy commissioner. Patient advocates praise him for trying to improve the predictability and efficiency of cancer-drug approvals. And he has expertise in food safety and animal health relevant skills in an era of bioterrorism and bird flu.

On some issues, however, Crawford already stands accused of lacking the independence and leadership skills required of the position. One bone of contention, which held up his Senate confirmation for several months, concerns access to an emergency contraceptive. Despite the approval of a panel of outside scientific experts, as well as the FDA's own staff scientists, Crawford had failed to act on an application from the manufacturer to make the 'morning after' contraceptive known as Plan B available over-the-counter. This month, the agency finally promised to make a decision by 1 September. The troubling implication is that until his nomination got bogged down in the Senate, Crawford bent to political pressure from an anti-abortion White House, instead of making a decision based on the best scientific evidence, which concluded that Plan B is safe and effective.

Crawford also seemed to be caught flat-footed last autumn, when the UK authorities shut down a Chiron plant in Liverpool, halving at a stroke last winter's US supply of flu vaccine. The FDA had failed to re-examine the plant after it had contamination problems in 2003 - even after the company reported, two months before it was shut down last October, that millions of doses of flu vaccine had been contaminated.

Additionally, consumer advocates are worried by a recent sharp decline in FDA enforcement actions against false or misleading advertising. FDA warning letters to pharmaceutical companies fell by $70 \%$ between January 2002 and December 2004, at a time when drug companies were pouring unprecedented sums into advertising directly aimed at consumers. Crawford was the FDA's top manager for much of this period.

Now his position has been confirmed, Crawford has more leverage, and he should have plenty of opportunities to demonstrate the leadership that the agency requires. Another flu-vaccine shortage looms this winter, and bird flu threatens the prospect of a 1918-style pandemic. Public suspicion of the pharmaceutical industry continues to grow in the wake of the Vioxx withdrawal (see Business, page 459), amid evidence that drug-makers are still slow to file evidence about the safety of established products with the regulator. In the face of these challenges, Crawford has to prove that he is the right man for the job. He could start by doing the right thing by Plan B. 